\title{
Overhead and Underground Distribution Systems Impact on Electric Vehicles Charging
}

\author{
Ahmed K. Allehyani and Mohammed J. Beshir
}

\begin{abstract}
There are two ways to distribute electric energy to customers: overhead lines and underground cables. Overhead lines and underground cables have different electrical characteristics. Underground cables have less resistance and inductance compared to overhead lines. Also, underground cables have more capacitance than overhead lines. This paper will test the voltage response of the system when electric vehicles are charged from overhead and underground distribution systems. The test will be done using IEEE 34 bus test feeder for the overhead distribution system. For the underground system, all overhead lines in IEEE 34 bus test feeder will be replaced with underground cables following the same electrical configuration.
\end{abstract}

Index Terms-Electric vehicles, IEEE 34, voltage violation, power distribution.

\section{INTRODUCTION}

\section{A. Underground Cable}

Underground cables are classified based on the number of core conductors. They commonly have one, two or three core conductors. Three core cables are used in most underground distribution systems because they are more economic than single core cables. Nonetheless, if the voltage exceeds $66 \mathrm{kV}$, three core cables are not practical because they become very heavy [1].

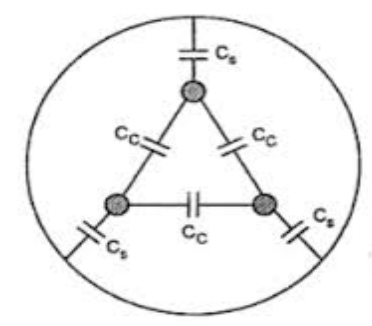

Fig. 1. The three core underground cable capacitance.

The capacitance of underground cables is important compared to overhead lines because conductors are located close to each other and close to the grounded sheath. Moreover, there is a dielectric material between the conductors that has larger permittivity than air.

Fig. 1 models the capacitance which occurs within the

Manuscript received October 8, 2014; revised April 10, 2015. The research was conducted under the ARRA Smart Grid Regional Demonstration Project funded by the US Department of Energy and City of Los Angeles Department of Water and Power.

Ahmed Allehyani is with the Department of Electrical Engineering at the University of Southern California, United States (e-mail: allehyaa@usc.edu).

Mohammed J. Beshir was with the Department of Electrical Engineering at the University of Southern California (USC), USA. underground cable. $\mathrm{Cc}$ and $\mathrm{Ce}$ represents the core to core capacitance, and conductor to earth capacitance respectively. $\mathrm{Cc}$ and $\mathrm{Ce}$ are caused by the electrostatic fields. The conductor-to-earth capacitors are wye-connected whereas the conductor-to-conductor capacitors are delta-connected.

\section{B. Overhead Lines}

Overhead lines consist of bare conductors which carry current. When lines carry current, some of the power carried gets dissipated in the line due to the resistance of the conductors. In case of alternating current, the losses will be greater when large cables are used due to the skin effect.

\section{Charging LeVEls [2]}

\section{A. Level 1}

Level 1 charges electric vehicles (EV's) through an alternating 120 volts. Level 1 does not require additional charging units. It can charge using the regular outlet that exists in modern houses. Therefore, there is no need for electric vehicles to be charged from charging stations. The charging time for electric vehicles to be charged fully depends on the battery used. However, it ranges between 4 to 11 hours on average. Moreover, customers who use level 1 usually charge their electric vehicles overnight.

\section{B. Level 2}

Level 2 provides power to electric vehicles through an alternating 240 volts. It requires additional charging units provided in public by the utility or set up in the customers' homes. Level 2 is the most common charging level because it has a relatively fast charging time and economic cost. The charging time depends on the type of battery used. However, level 2 can charge an electric vehicle in 2 to 6 hours.

\section{Level 3}

Level 3 charges electric vehicles through a direct 480 volts. Level 3 requires additional charging units to convert the voltage from AC to DC. Therefore, it is not recommended to install it in areas that are populated. Level 3 is the fastest charging level. Level 3 charging needs approximately 24 minutes to an hour to charge the electric vehicle. The main disadvantage of this level of charging is its cost. It is expensive to install the charging units.

\section{MODELING}

The simulation will be performed on the IEEE 34 bus test feeder, shown in Fig. 2, using EDD software as shown in Fig. 3. The distribution system exists in Arizona. The system voltage is $24.9 \mathrm{kV}$. The system has a step down transformer 
with a turn ratio of 24.9:4.16. Two voltage regulators are installed in the system to maintain a good voltage profile. The IEEE34 bus test feeder is entirely overhead. It is a combination of single phase and three phase lines. Some of the loads are single phase and the others are three phase. Spot loads are nodes $830,844,860,840,890$ and 848 . On the other hand, distributed loads are distributed on the other nodes. The same IEEE34 bus test bus feeder will be used to simulate the overhead distribution system [3]. However, to simulate the underground system, the same system is used but with underground cables. All overhead lines are removed and replaced with underground cables [4].

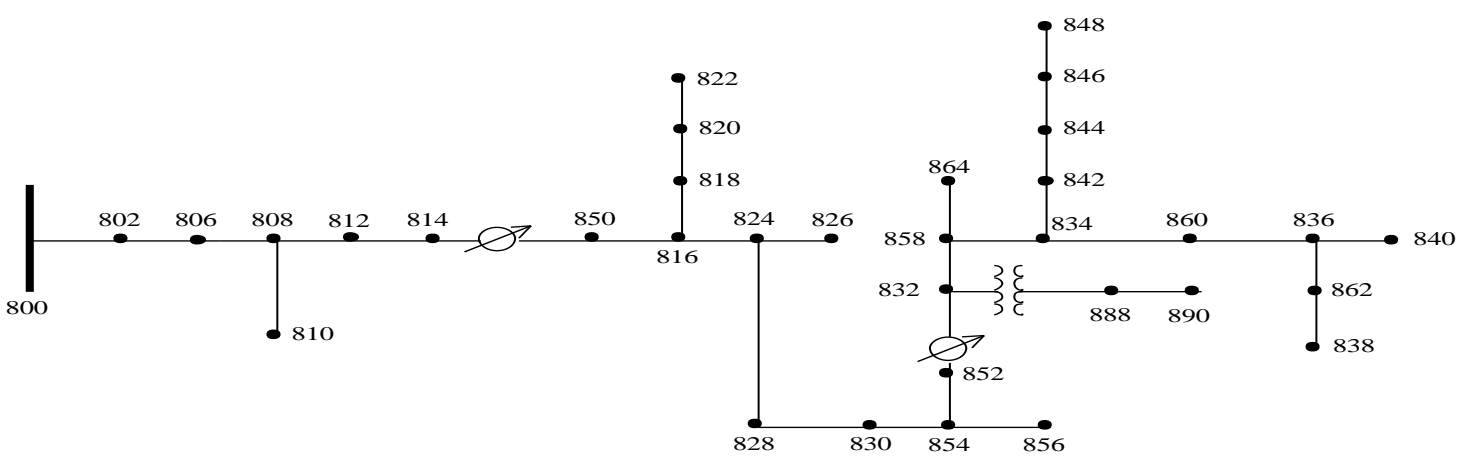

Fig. 2. The IEEE 34 bus test feeder.

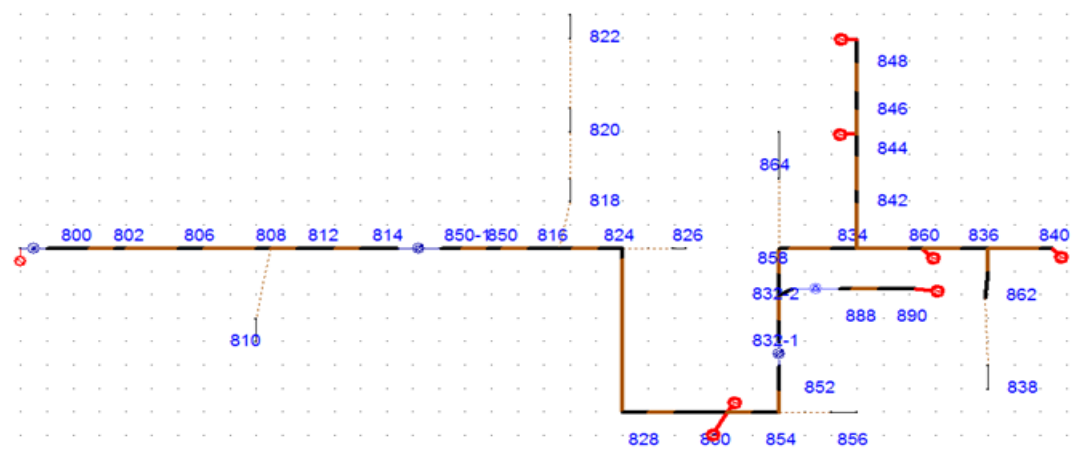

Fig. 3. The EDD model of the IEEE 34 bus test feeder.

\section{ASSUMPTIONS}

\section{A. Load Curve Assumptions}

Customers' demands vary instantaneously. It could be classified into peak demand and off-peak demand. The peak demand describes the period when the electrical demand reaches the highest point, or the period in which the customers are consuming the highest rate of power. Peak demand varies with respect to many factors such as the season of the year and whether the day is a holiday or not. On the other hand, the off-peak demand is the period that is not included in the peak period.

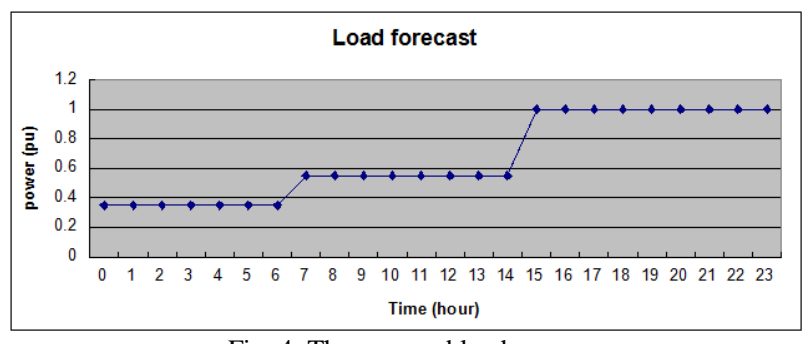

Fig. 4. The assumed load curve.

The impact of the distribution system type on the number of electric vehicles charged will be tested in three periods: morning, evening and afternoon. The peak period is the afternoon with $100 \%$ of the capacity. On the other hand, the morning and evening are assumed $55 \%$ and $35 \%$ respectively as shown in Fig. 4.

\section{B. Underground Cables Model}

For the overhead system, the same lines used in the IEEE 34 bus test feeder are used which are Aluminum steel reinforced. However, $500 \mathrm{MCM}$ cables are used with the underground system.

\section{TEST}

Each bus is tested separately. The overhead distribution system will be tested first. Electric vehicles are connected to spot nodes. Taking each spot node separately, electric vehicles are increased until a violation occurs in the system. The violation could be in the voltage or in the maximum current allowed to pass through the regulators. Acceptable voltage variation is taken to be within $\pm 8.2 \%$. Also, regulators are allowed to be loaded up to $20 \%$ more than the rated current. Then, the same will be done at each node. Bus 890 will not be loaded because it is connected to a transformer that regulates the voltage variation. The previous process will be repeated for the underground distribution system. After that, five spot buses will be loaded at the same time using both the overhead and underground systems. This is done to examine the system behavior in case of loading several buses simultaneously.

\section{RESULTS}

The following tables show the total active power 
connected. The connected active power represents electric vehicles. Also, how many electric vehicles it is equivalent to using charging level 1 and 2 .

\section{A. Loading Each Node Separately}
1) Night
a) Overhead

TABLE I: THE MAX Number of EV's That CAN Be CONNECTED AT EACH Bus

\begin{tabular}{|c|c|c|c|}
\hline Bus & \multicolumn{3}{|c|}{ Overhead } \\
\hline & Active Power(kW) & Level 1 & Level 2 \\
\hline 840 & 3000 & 1500 & 375 \\
\hline 860 & 3050 & 1525 & 381 \\
\hline 848 & 3000 & 1500 & 375 \\
\hline 844 & 3050 & 1525 & 381 \\
\hline 830 & 3500 & 1750 & 437 \\
\hline
\end{tabular}

\section{b) Underground}

TABLE II: THE MAX NumBer of EV'S THAT CAN BE CONNECTED AT EACH

\begin{tabular}{|c|c|c|c|}
\hline Bus & \multicolumn{3}{|c|}{ Underground } \\
\hline & Active Power(kW) & Level 1 & Level 2 \\
\hline 840 & 3600 & 1800 & 450 \\
\hline 860 & 3600 & 1800 & 450 \\
\hline 848 & 3600 & 1800 & 450 \\
\hline 844 & 3600 & 1800 & 450 \\
\hline 830 & 3650 & 1825 & 456 \\
\hline
\end{tabular}

Table I and Table II examined the system response when the electric vehicles were connected at night where the minimum load usually occurs. The underground system was able to withstand more Charged EV's compared to the overhead system. Additionally, the system did not experience overvoltage at low loading due to the overall capacitance effect of the underground system.

\section{2) Morning}

\section{a) Overhead}

Tables III and IV show the maximum number of EV's connected to the overhead and underground systems in the morning. The underground system was able to endure more electric vehicles.

TABLE III: The MAX Number of EV's That CAN BE CONNECTED AT EACH BUS

\begin{tabular}{|c|c|c|c|}
\hline Bus & \multicolumn{3}{|c|}{ Overhead } \\
\hline & Active Power(kW) & Level 1 & Level 2 \\
\hline 840 & 1650 & 825 & 206 \\
\hline 860 & 1700 & 850 & 212 \\
\hline 848 & 1650 & 825 & 206 \\
\hline 844 & 1700 & 850 & 212 \\
\hline 830 & 2000 & 1000 & 250 \\
\hline
\end{tabular}

\section{b) Underground}

TABLE IV: THE MAX NUMBER OF EV'S THAT CAN BE CONNECTED AT EACH BUS

\begin{tabular}{|c|c|c|c|}
\hline Bus & \multicolumn{3}{|c|}{ Underground } \\
\hline & Active Power(kW) & Level 1 & Level 2 \\
\hline 840 & 2100 & 1050 & 262 \\
\hline 860 & 2100 & 1050 & 262 \\
\hline 848 & 2100 & 1050 & 262 \\
\hline 844 & 2100 & 1050 & 262 \\
\hline 830 & 2200 & 1100 & 275 \\
\hline
\end{tabular}

\section{3) Afternoon}

a) Overhead

When EV's are charged in the afternoon when the peak period occurs, the underground system showed more endurance as shown in Table V and Table VI.

TABLE V: The MAX Number of EV's That CAN BE CONNECTED AT EACH BUS

\begin{tabular}{|c|c|c|c|}
\hline Bus & \multicolumn{3}{|c|}{ Overhead } \\
\hline & Active Power(kW) & Level 1 & Level 2 \\
\hline 840 & 580 & 290 & 72 \\
\hline 860 & 590 & 295 & 73 \\
\hline 848 & 580 & 290 & 72 \\
\hline 844 & 600 & 300 & 75 \\
\hline 830 & 650 & 325 & 81 \\
\hline
\end{tabular}

\section{b) Underground}

TABLE VI: THE MAX Number of EV's That CAN BE CONNECTED AT EACH BUS

\begin{tabular}{|c|c|c|c|}
\hline Bus & \multicolumn{3}{|c|}{ Underground } \\
\hline & Active Power(kW) & Level 1 & Level 2 \\
\hline 840 & 950 & 475 & 118 \\
\hline 860 & 950 & 475 & 118 \\
\hline 848 & 950 & 475 & 118 \\
\hline 844 & 950 & 475 & 118 \\
\hline 830 & 950 & 475 & 118 \\
\hline
\end{tabular}

\section{B. Increase Five Spot Buses at the Same Time}

\section{1) Overhead}

On the other hand, Table VII and Table VIII show the system response when EV's are connected to all load buses at the same time. The underground system was able to withstand more EV's.

TABLE VII: THE MAX NuMBER OF EV'S THAT CAN BE CONNECTED AT EACH Bus When SpOt Nodes ARE LOADED at the SAME Time

\begin{tabular}{|c|c|c|c|}
\hline & & Overhead & \\
\hline & Power increase $(\mathrm{kW})$ & Level 1 & Level 2 \\
\hline Night & 610 & 305 & 76.25 \\
\hline Morning & 350 & 175 & 43.75 \\
\hline Afternoon & 120 & 60 & 15 \\
\hline
\end{tabular}




\section{2) Underground}

TABLE VIII: THE MAX NUMBER OF EV'S THAT CAN BE CONNECTED AT EACH Bus When Spot Nodes ARE LOADED AT THE SAME Time

\begin{tabular}{|c|c|c|c|}
\hline Time Period & & Underground & \\
\hline & Power increase $(\mathrm{kW})$ & Level 1 & Level 2 \\
\hline Night & 720 & 360 & 90 \\
\hline Morning & 430 & 215 & 53.75 \\
\hline Afternoon & 190 & 95 & 23.75 \\
\hline
\end{tabular}

Therefore, underground distribution system was able to withstand more connected in all scenarios. This is due to the capacitance effect of the underground cable and the high resistance of the overhead distribution lines [5].

The following figures, from Fig. 5 to Fig. 8, show how many more EV's can be connected to the IEEE 34 underground bus system.

In conclusion, underground distribution system was able to withstand more charged electric vehicles in all scenarios. Therefore, from a technical point of view, it is recommended to use underground distribution system to accommodate more charged EV's without resulting a violation of any sort.

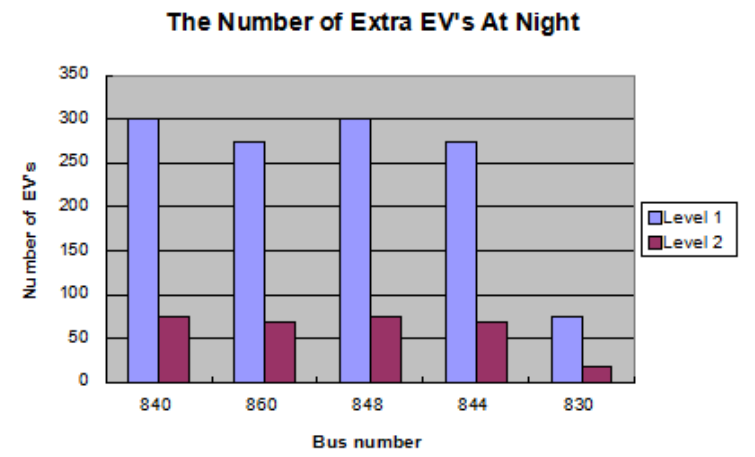

Fig. 5. The number of extra EV's that could be charged at night for each bus at night.

The Number of Extra EV's In The Morning

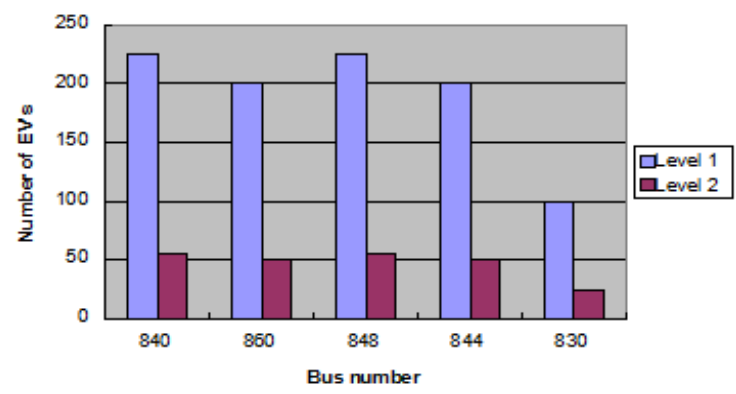

Fig. 6. The number of extra EV's that could be charged at night for each bus in the morning.

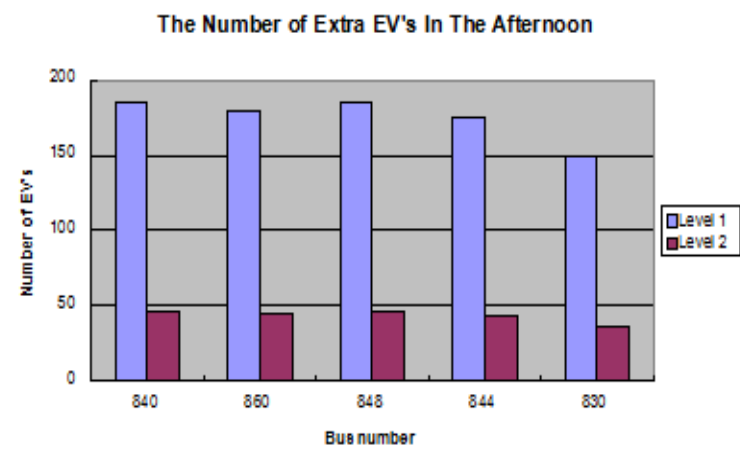

Fig. 7. The number of extra EV's that could be charged at night for each bus in the morning.
The Number of Extra EV's

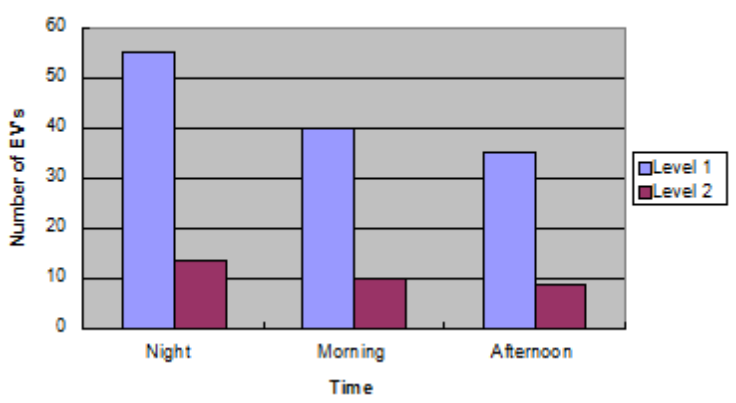

Fig. 8. The number of extra EV's that could be charged from all buses at the same time.

\section{ACKNOWLEDGMENT}

This paper was prepared while taking a directed research at the University of Southern. I would like to thank Professor Mohammed Beshir for supervising me while doing the research. Also, I am grateful to his research assistants Laith Shalalfeh and Zeming Jiang for the help they provided.

\section{REFERENCES}

[1] V. K. Mehta and R. Mehta, Principles of Power System: (Including Generation, Transmission, Distribution, Switchgear and Protection),. 4th ed. New Delhi: S. Chand, 2005, p. 288.

[2] M. Yilmaz and P. T. Krein, "Review of charging power levels and infrastructure for plug-in electric and hybrid vehicles," in Proc. 2012 IEEE International Electric Vehicle Conference, 2012, pp. 1-8, 4-8.

[3] Radial Test Feeders - IEEE Distribution System Analysis Subcommittee. [Online]. Available: http://www.ewh.ieee.org/soc/pes/dsacom/testfeeders.html

[4] B. Cunningham and H. Zadehgol, "Underground urban distribution cables, ampacity analysis and capacity improvements in Seattle City Light system," Transmission and Distribution Conference and Exposition, vol. 1, pp. 183-188, 2001.

[5] G. J. Newton, "Underground distribution systems, " Proceedings of the American Institute of Electrical Engineers, vol. 35, no. 8, pp. 1193-1208, Aug. 1916

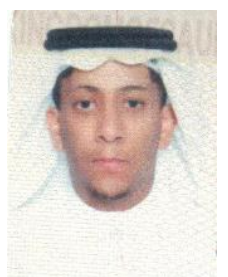

Ahmed K. Allehyani was born in Jeddah, Saudi Arabia on April 1, 1990. He earned his bachelor's degree from King Abdulaziz University in Jeddah, Saudi Arabia. He graduated from King Abdulaziz University in 2012 with a bachelor degree of science in electrical engineering.

He did summer training at the Saudi Electricity Company in the distribution department for two months. After graduation, he worked also for the Saudi Electricity Company but in the transmission department. He was hired as a project manager for the electricity transmission projects. He quitted his job to get a master of science degree from the University of Southern California which located in Los Angeles, CA, United States. He is currently studying MSc in electrical engineering at the University of Southern California.

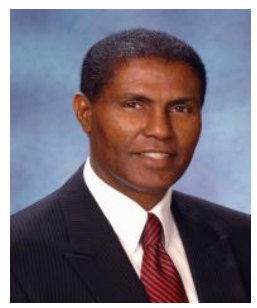

Mohammed J. Beshir is an associate professor of electrical engineering at the University of Southern California (USC), USA. He has a Ph.D. degree in electrical engineering from USC and master's degree in business administration (MBA) from Pepperdine University in Malibu, California, USA $\mathrm{He}$ is a registered professional engineer in the state of California and is a senior member of IEEE.

Formerly, he was an assistant director of Power System Planning and Development Division at the Los Angeles Department of Waterand Power (LADWP). He worked for LADWP for over 30 years in various responsibilities including integrated resource planning, transmission planning, renewable project development, HVDC design, power contracts, distribution planning, power reliability, and energy storage systems. 